\title{
Cellular and Molecular Engineering in Transition
}

Cellular and Molecular Bioengineering (CMBE) is now entering its sixth year of publication. Under the leadership of its Co-Editors-in-Chief (EICs), Ed Guo and David Odde, it has achieved an excellent record in its short history. Providing expertise from the engineering and biological sectors, Drs. Guo and Odde drew from these communities to publish important reports of exciting multidisciplinary work occurring at the interface of life sciences, engineering and medicine. To assist and support the undertaking of this new journal in a rapidly growing field in biomedical engineering, an Editorial Advisory Board (EAB) was formed and chaired by Dr. Van Mow. The EAB served a key role in promoting the journal and raising the level of interest in potential authors and readers. Working in concert with the Co-EICs and the EAB, an international group of experts in CMBE comprised the Board of Associate Editors.

The overarching aim of CMBE remains the same as that outlined in the editorial by Shu Chien (past President), Ajit Yoganathan (past Publications Board Chair), and Van Mow (past EAB Chair) published in the first volume of the journal in March 2008, "to integrate our understanding of mechanical, chemical, and electrical processes to better understand the integrated, systems nature of cellular processes." To that end, CMBE has served the community well and is being recognized as a leading journal in the field.

At the five-year juncture from the start of the journal, the Co-EICs have fulfilled their vision enunciated in their editorial in the March 2008 issue that launched the journal. Their hard work and dedication have been keys to the success of CMBE. Now that the founding EICs have relinquished their shared editorship, CMBE will move forward with Dr. Michael R. King serving as Editor-in-Chief.

To the previous Co-Editors-in-Chief, members of the Board of Associate Editors and members of the Editorial Advisory Board, on behalf of the Biomedical Engineering Society, we express our sincere thanks and appreciation for their critical and important contributions to the success of CMBE. We express our best wishes to Editor-in-Chief Michael King and encourage researchers in the field to continue to choose CMBE as the journal to convey frontier discoveries.

\section{Gilda BARABINO}

President, Biomedical Engineering Society,

Landover, MD, USA

The Wallace H. Coulter Department of Biomedical Engineering, Georgia Institute of Technology and Emory University, Atlanta, GA, USA

Electronic mail: barabino@gatech.edu

Shu Chien

Past President, Biomedical Engineering Society, Landover, MD, USA

Department of Bioengineering, University of

California at San Diego, San Diego, CA, USA

Frank Yin

Publications Board Chair, Biomedical Engineering Society, Landover, MD, USA

Department of Biomedical Engineering, Washington University, St. Louis, MO, USA 